\begin{tabular}{|c|c|c|}
\hline Case Reports in & \multicolumn{2}{|c|}{ Case Rep Gastroenterol 2019;13:410-417 } \\
\hline Gastroenterology & $\begin{array}{l}\text { DOI: } 10.1159 / 000503169 \\
\text { Published online: September 27, } 2019\end{array}$ & $\begin{array}{l}\text { ○ } 2019 \text { The Author(s) } \\
\text { Published by S. Karger AG, Base } \\
\text { www.karger.com/crg }\end{array}$ \\
\hline & $\begin{array}{l}\text { This article is licensed under the } \mathrm{Cr} \\
\text { International License (CC BY-NC) (ht } \\
\text { Usage and distribution for commercial }\end{array}$ & $\begin{array}{l}\text { nons Attribution-NonCommer } \\
\text { ger.com/Services/OpenAccess } \mathrm{L} \\
\text { uires written permission. }\end{array}$ \\
\hline
\end{tabular}

\title{
Combined Intestinal Adenomas/Microcarcinoids
}

\author{
Hiromi Tamura Hiroka Ando Reiko Doi Shiro Adachi \\ Department of Pathology, Toyonaka Municipal Hospital, Toyonaka, Japan
}

\section{Keywords}

Combined intestinal adenoma-microcarcinoid - Microcarcinoid · Carcinoid · Neuroendocrine tumor $\cdot$ Large intestine

\begin{abstract}
The combined colonic adenoma/microcarcinoid tumor is a rare intestinal neoplasm featuring intermingled adenomatous and carcinoid components. A few case reports and small case series have suggested that this entity exhibits an indolent clinical course. Here, we report two cases with these tumors, and describe the morphological features and clinical follow-up. A 61year-old male and 78-year-old male presented with heme-positive stools at their medical checkups. Colonoscopy revealed masses in the colons; we performed endoscopic mucosal resection. Both lesions featured low-grade adenomas and low-grade neuroendocrine tumors. We diagnosed combined colonic adenomas/microcarcinoids. The clinical courses of both patients were benign at follow-up at 2.5 and 6 years. Awareness of this rare colonic tumor should prevent potential diagnostic pitfalls and may help clarify the natural history of these tumors and their possible relationships with composite glandular/carcinoid tumors.
\end{abstract}

(C) 2019 The Author(s)

Published by S. Karger AG, Basel 
Tamura et al.: Combined Intestinal Adenomas/Microcarcinoids

\section{Introduction}

Although subtle neuroendocrine differentiation detected histologically or immunohistochemically is common in colonic adenomas/adenocarcinomas, colonic tumors featuring significant proportions of morphologically recognizable neuroendocrine components are uncommon. When both the glandular and neuroendocrine components of a lesion exhibit benign morphologies, the lesion is termed combined adenoma/carcinoid tumor; when the carcinoid component is minute or microscopic, the tumor is termed combined adenoma/microcarcinoid tumor [1]. Although the natural history of colonic adenoma/microcarcinoid tumors remains largely unknown (because the entity is rare), a few case reports and small case series have suggested that these tumors are not aggressive [2-10]. Here, we present two cases of adenomatous polyps containing morphologically recognizable neuroendocrine components. Unlike carcinoid components, microcarcinoid components are less readily recognized histologically and therefore pose unique diagnostic challenges.

\section{Case Presentation}

Case 1

A 61-year-old Japanese male with a history of irritable bowel syndrome and diabetes mellitus presented with heme-positive stools at a medical checkup. Although he had diarrhea for 2 months 1 year before, ramosetron hydrochloride (5-HT3 antagonist) was effective. There were no abnormalities in physical examinations. Blood test results showed normal hemoglobin $14.9 \mathrm{~g} / \mathrm{dL}$ (13.5-17.5 g/dL), increased aspartate aminotransferase $38 \mathrm{U} / \mathrm{L}$ (10-37 $\mathrm{U} / \mathrm{L}$ ), alanine aminotransferase $42 \mathrm{U} / \mathrm{L}$ (4-40 U/L), $\gamma$-glutamyltranspeptidase $68 \mathrm{U} / \mathrm{L}$ (11-64 $\mathrm{U} / \mathrm{L}$ ), glucose $236 \mathrm{mg} / \mathrm{dL}(60-110 \mathrm{mg} / \mathrm{dL})$, and C-reactive protein $1.41 \mathrm{mg} / \mathrm{dL}(<0.3 \mathrm{mg} / \mathrm{dL})$. Colonoscopy revealed a 15-mm diameter mass in the descending colon (Fig. 1a). Endoscopic mucosal resection (EMR) was performed. The patient is currently doing well without any recurrence or metastasis at 6 years after EMR.

\section{Case 2}

A 78-year-old Japanese male with a history of prostate carcinoma, viral hepatitis, and diabetes mellitus presented with heme-positive stools at a medical checkup. He did not have carcinoid syndrome-like symptoms such as diarrhea or flushing. Physical examination was entirely unremarkable. Laboratory results included normal hemoglobin $15.3 \mathrm{~g} / \mathrm{dL}$ (13.5-17.5 $\mathrm{g} / \mathrm{dL})$, increased creatinine $1.00 \mathrm{mg} / \mathrm{dL}(0.3-0.9 \mathrm{mg} / \mathrm{dL})$, total cholesterol $229 \mathrm{mg} / \mathrm{dL}$ (130$219 \mathrm{mg} / \mathrm{dL}$ ), triglyceride $209 \mathrm{mg} / \mathrm{dL}(<149 \mathrm{mg} / \mathrm{dL})$, glucose $145 \mathrm{mg} / \mathrm{dL}(60-110 \mathrm{mg} / \mathrm{dL})$, and carbohydrate antigen (CA) 19-9 $50 \mathrm{U} / \mathrm{mL}(<37 \mathrm{U} / \mathrm{mL})$. Colonoscopy revealed an 8-mm diameter mass in the ascending colon (Fig. 1b). The tumor was removed via EMR. The patient remains well without any evidence of tumor recurrence or metastasis 2 years and 6 months after EMR.

\section{Pathological Findings}

Both tumors were polypoid in nature and were predominantly composed of conventional low-grade adenomatous tissue (Fig. 2a, 3a). In case 1, cells with uniform rounded nuclei and eosinophilic granular cytoplasm were evident in the adenoma; the features were characteristic of neuroendocrine differentiation. The cells were arranged in clusters or cords, or were individually dispersed (Fig. 2b), and were intimately intermingled with the adenomatous 


\section{Case Reports in Gastroenterology}

Case Rep Gastroenterol 2019;13:410-417 DOI: $10.1159 / 000503169$

(c) 2019 The Author(s). Published by S. Karger AG, Basel www.karger.com/crg

Tamura et al: Combined Intestinal Adenomas/Microcarcinoids

component. Immunohistochemical staining revealed diffuse expression of synaptophysin and CD56, but not chromogranin-A (Fig. 2c). The nuclei were strongly reactive for $\beta$-catenin (Fig. $2 \mathrm{~d}$ ) and did not exhibit significant atypia or mitotic figures. The Ki-67 labeling index was $1.45 \%$. In case 2 , a distinct neuroendocrine component composed of solid nests was evident at the base of the conventional low-grade adenoma (Fig. 3b). The cells exhibited uniform rounded nuclei, and large, granular eosinophilic cytoplasms. Immunohistochemically, the cells were weakly positive for synaptophysin and CD56, but negative for chromogranin-A (Fig. $3 c$ ). The nuclei were strongly reactive for $\beta$-catenin (Fig. 3d). The Ki-67 labeling index was $0.99 \%$.

\section{Discussion}

Mixed neuroendocrine/exocrine neoplasms of the large intestine are uncommon. These glandular neoplasms contain morphologically recognizable endocrine components constituting substantial proportions of the tumors [9], which span broad biological and clinical spectra ranging from intermediate-grade goblet cell carcinoids to high-grade tumors such as mixed adenocarcinomas/small cell carcinomas. The combined adenoma/carcinoid tumor is a rare and distinctive member of this group, characterized by bland histology and a favorable natural history. The adenomatous tumor intermingles with a detectable but small carcinoid component; it is necessary to exclude a collision tumor and an adenoma with a few scattered neuroendocrine cells [2-10]. The intimate association between the two morphological components suggests that both tumor types arise from a common cell. Although the morphologies of the carcinoid and adenomatous components differ, molecular studies have suggested that both components originate from a common multipotent stem cell $[2,11]$. Indeed, in vitro studies using non-transformed and immortal cells derived from rat ileal crypt cells have shown that such cells can transform into cells containing adenoma-like messenger ribonucleic acid (mRNA) and proteins, and cells expressing the serotonin receptor gene that exhibit neuroendocrine cell-like morphology [12]. Therefore, it is probable that a single stem cell proliferates and differentiates into both adenomatous and carcinoid components, creating a mixed adenoma/carcinoid tumor.

A neuroendocrine tumor is defined by the presence of an endocrine cell growth greater than $0.5 \mathrm{~mm}$ in diameter. A microcarcinoid tumor is defined when the tumor is between 0.5 $\mathrm{mm}$ and $0.5 \mathrm{~cm}$ in diameter and is not evident endoscopically [1]. It cannot yet be conclusively determined whether microcarcinoid tumors within adenomatous polyps are precursors of combined adenoma/carcinoid tumors or are related but distinct entities. As the distinction between microcarcinoid and carcinoid tumors depends (arbitrarily) on size only, it is probable that adenoma/microcarcinoid tumors are precursors of adenoma/carcinoid tumors. Thus, as discussed above, it is probable that mixed adenoma/microcarcinoid tumors originate from a single stem cell.

A few studies have explored the biological differences between carcinoid components associated with adenomas and sporadic, intestinal carcinoid tumors. Estrella et al. [2] found that the carcinoid components of adenomas exhibited significantly higher mean $\beta$-catenin scores than sporadic carcinoid tumors, suggesting that the latter tumors may develop via a pathway distinct from that giving rise to adenoma/carcinoid tumors. The strong, diffuse nuclear positivity for $\beta$-catenin suggests inactivation of the adenomatous polyposis coli (APC) gene in carcinoid components associated with adenomas, which is of pathogenetic interest. Most conventional colorectal adenocarcinomas commence as low-grade adenomas after inactivation of the 
APC gene [13]. The fact that this gene is inactivated in both the carcinoid and adenomatous components supports the hypothesis that both components are derived from a common stem cell. One report found that the overall survival of patients with adenoma/carcinoid tumors was significantly lower than that of patients with sporadic intestinal carcinoid tumors, but no patients in the former group died [3]. Therefore, the prognoses of patients with either type of tumor do not seem to differ.

In the gastrointestinal tract, mixed glandular/endocrine tumors include adenoma/carcinoid and adenocarcinoma/carcinoid tumors, and adenoma/neuroendocrine and adenoneuroendocrine carcinomas [14]. As the molecular profiles of endocrine carcinomas differ markedly from those of carcinoid tumors [11], it is believed that adenoneuroendocrine carcinomas arise via transdifferentiation from preexisting adenocarcinomas, and not via malignant progression of preexisting carcinoid tumors. Therefore, although adenoma/carcinoid tumors can progress to adenocarcinoma/carcinoid tumors, it is unlikely that the other two combinations (adenoma/neuroendocrine and adenoneuroendocrine carcinomas) are derived from adenoma/carcinoid tumors.

Carcinoid or microcarcinoid tumors arise from stem cells in the crypt base, proliferate in the lamina propria, and invade the submucosal layer. Microcarcinoid tumors are small and can serve as precursors of carcinoid tumors; the former tumors are usually found in the lamina propria. During progression to carcinoid tumors, the microcarcinoid tumor cells proliferate, as do stromal fibroblasts, closely mimicking a desmoplastic reaction to an invasive carcinoma. Thus, in cases with adenoma/carcinoid tumors, stromal fibroblastic proliferation around the carcinoid components creates a risk of serious misinterpretation. An adenocarcinomatous invasion may be mistakenly diagnosed, and the malignant potential of the glandular neoplasm is in fact low [6]. Careful observation of the cytological features of both the carcinoid and adenomatous components, and meticulous immunohistochemical examination, will prevent misdiagnosis of an invasive carcinoma.

Another possible misinterpretation of an adenoma/microcarcinoid tumor, although clinically less serious, is the rare metaplastic change termed the squamous morula. This can arise in colonic adenomatous glands and may be morphologically indistinguishable from a carcinoid tumor. The cells are relatively small, slightly eosinophilic, and contain bland round to oval nuclei. Morulae are immunopositive for cytokeratin (CK) 5/6, as are microcarcinoid/carcinoid tumors, but are negative for neuroendocrine markers $[6,15]$. Notably, the status of the squamous differentiation marker, p63, is not helpful; most squamous morulae and colonic adenomas do not express this marker [15]. In case 2 of this report, a structure similar to a morula was found in and around the adenomatous glands. This structure was immunoreactive for CK5/6 but negative for p63; a significantly higher proportion of cells (compared to the glandular component) stained with anti-synaptophysin antibody. Thus, not only the immunohistochemical profile indicated that neuroendocrine differentiation was in play; the cytoplasmic eosinophilic granularity was also suggestive. Therefore, we considered that the structure was a microcarcinoid tumor, not a squamous morula.

The malignant potential of adenoma/microcarcinoid tumors is unclear. Although Lin et al. [5] reported a case in which an adenoma/microcarcinoid tumor metastasized to a lymph node, the tumor morphology shown in a figure of the cited work is suggestive of a goblet cell carcinoid tumor (an amphicrine tumor exhibiting both adenocarcinomatous features and neuroendocrine differentiation) rather than an adenoma/microcarcinoid tumor. No convincing report has linked an adenoma/microcarcinoid tumor to a nodal or distant metastasis. Because these tumors are rare, and as no consensus treatment is yet available, we hope that increased awareness of the entity will improve diagnosis. Larger patient series are required to allow 
more definitive studies of the natural history and the clinical, pathological, and biological characteristics of this rare entity.

\section{Statement of Ethics}

The Ethics Committee of Toyonaka Municipal Hospital does not require ethics approval for reporting individual cases; however, the general informed consent includes patient's approval for use of relevant clinical and surgical information and photos in an anonymous way.

\section{Disclosure Statement}

The authors have no conflict of interest.

\section{Author Contributions}

Conceptualization: Hiromi Tamura, Shiro Adachi. Data curation: Hiromi Tamura, Hiroka Ando, Reiko Doi, Shiro Adachi. Formal analysis: Hiromi Tamura. Investigation: Hiromi Tamura. Writing of the original draft: Hiromi Tamura. Writing, review, and editing: Hiromi Tamura, Shiro Adachi. All of the authors read and approved the final version of the manuscript.

\section{References}

1 Cockburn A, Rege TA. Gastrointestinal neuroendocrine lesions. In: Noffsinger AE, editor. Fenoglio-Preiser's Gastrointestinal Pathology. 4th ed. Philadelphia: Wolters Kluwer; 2017, p. 1004-1068.

2 Estrella JS, Taggart MW, Rashid A, Abraham SC. Low-grade neuroendocrine tumors arising in intestinal adenomas: evidence for alterations in the adenomatous polyposis coli/ $\beta$-catenin pathway. Hum Pathol. 2014 Oct;45(10):2051-8.

3 Moyana TN, Qizilbash AH, Murphy F. Composite glandular-carcinoid tumors of the colon and rectum. Report of two cases. Am J Surg Pathol. 1988 Aug;12(8):607-11.

4 Lyda MH, Fenoglio-Preiser CM. Adenoma-carcinoid tumors of the colon. Arch Pathol Lab Med. 1998 Mar;122(3):262-5.

5 Lin J, Goldblum JR, Bennett AE, Bronner MP, Liu X. Composite intestinal adenoma-microcarcinoid. Am J Surg Pathol. 2012 Feb;36(2):292-5.

6 Salaria SN, Abu Alfa AK, Alsaigh NY, Montgomery E, Arnold CA. Composite intestinal adenomamicrocarcinoid clues to diagnosing an under-recognised mimic of invasive adenocarcinoma. J Clin Pathol. 2013 Apr;66(4):302-6.

7 Li Y, Yau A, Schaeffer D, Magliocco A, Gui X, Urbanski S, et al. Colorectal glandular-neuroendocrine mixed tumor: pathologic spectrum and clinical implications. Am J Surg Pathol. 2011 Mar;35(3):413-25.

8 Kim MJ, Lee EJ, Kim DS, Lee DH, Youk EG, Kim HJ. Composite intestinal adenoma-microcarcinoid in the colon and rectum: a case series and historical review. Diagn Pathol. 2017 Nov;12(1):78.

9 Pulitzer M, Xu R, Suriawinata AA, Waye JD, Harpaz N. Microcarcinoids in large intestinal adenomas. Am J Surg Pathol. 2006 Dec;30(12):1531-6.

10 Lewin K. Carcinoid tumors and the mixed (composite) glandular-endocrine cell carcinomas. Am J Surg Pathol. 1987;11 Suppl 1:71-86.

11 Vortmeyer AO, Lubensky IA, Merino MJ, Wang CY, Pham T, Furth EE, et al. Concordance of genetic alterations in poorly differentiated colorectal neuroendocrine carcinomas and associated adenocarcinomas. J Natl Cancer Inst. 1997 Oct;89(19):1448-53.

12 Gordon PV, Paxton JB, Fox NS. A methodology for distinguishing divergent cell fates within a common progenitor population: adenoma- and neuroendocrine-like cells are confounders of rat ileal epithelial cell (IEC-18) culture. BMC Cell Biol. 2005 Jan;6(1):2. 


\section{Case Reports in \\ Gastroenterology}

\begin{tabular}{l|l}
\hline Case Rep Gastroenterol 2019;13:410-417 \\
\hline DOI: 10.1159/000503169 & $\begin{array}{l}\text { (c) 2019 The Author(s). Published by S. Karger AG, Basel } \\
\text { www.karger.com/crg }\end{array}$ \\
\hline
\end{tabular}

Tamura et al.: Combined Intestinal Adenomas/Microcarcinoids

13 Powell SM, Zilz N, Beazer-Barclay Y, Bryan TM, Hamilton SR, Thibodeau SN, et al. APC mutations occur early during colorectal tumorigenesis. Nature. 1992 Sep;359(6392):235-7.

14 La Rosa S, Sessa F, Uccella S. Mixed neuroendocrine-nonneuroendocrine neoplasms (MiNENs): unifying the concept of a heterogeneous group of neoplasms. Endocr Pathol. 2016 Dec;27(4):284-311.

15 Mochizuki K, Kondo T, Oishi N, Tahara I, Inoue T, Kasai K, et al. Squamous morula formation in colorectal adenoma: immunohistochemical and molecular analyses. Pathol Res Pract. 2015 Oct;211(10):797-800.

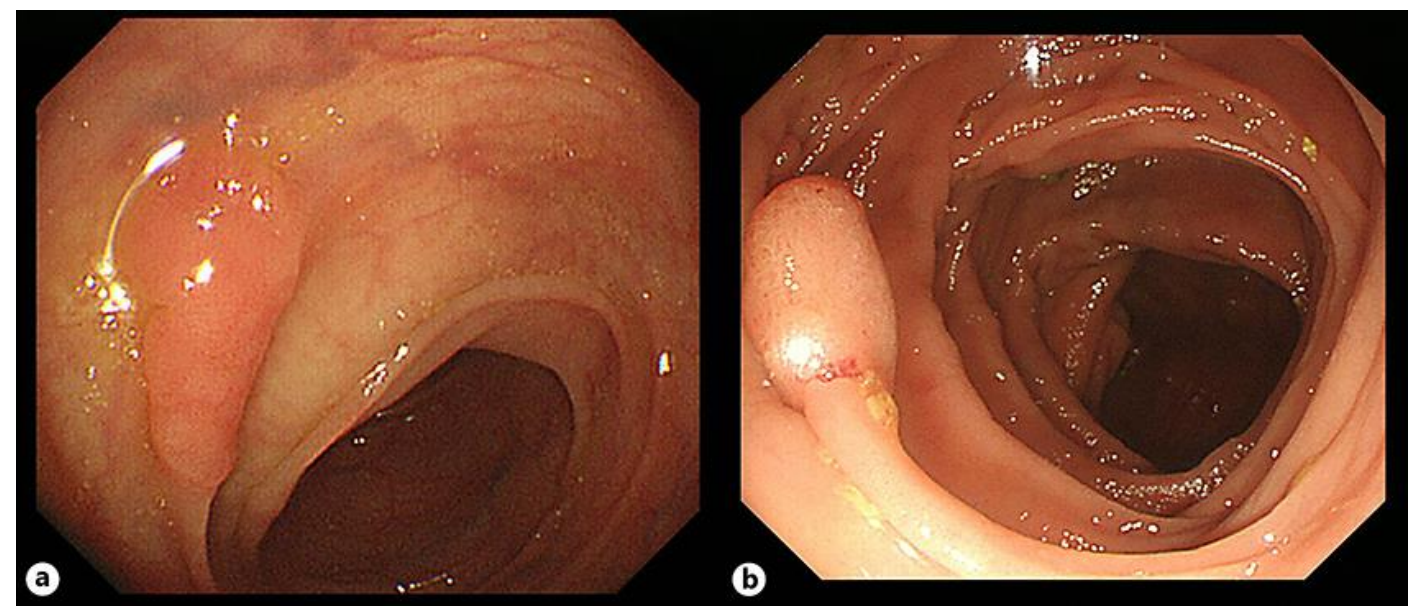

Fig. 1. Endoscopic views of case 1 (a) and case 2 (b). Both cases exhibited well-circumscribed and slightly elevated lesions. 


\section{Case Reports in Gastroenterology}
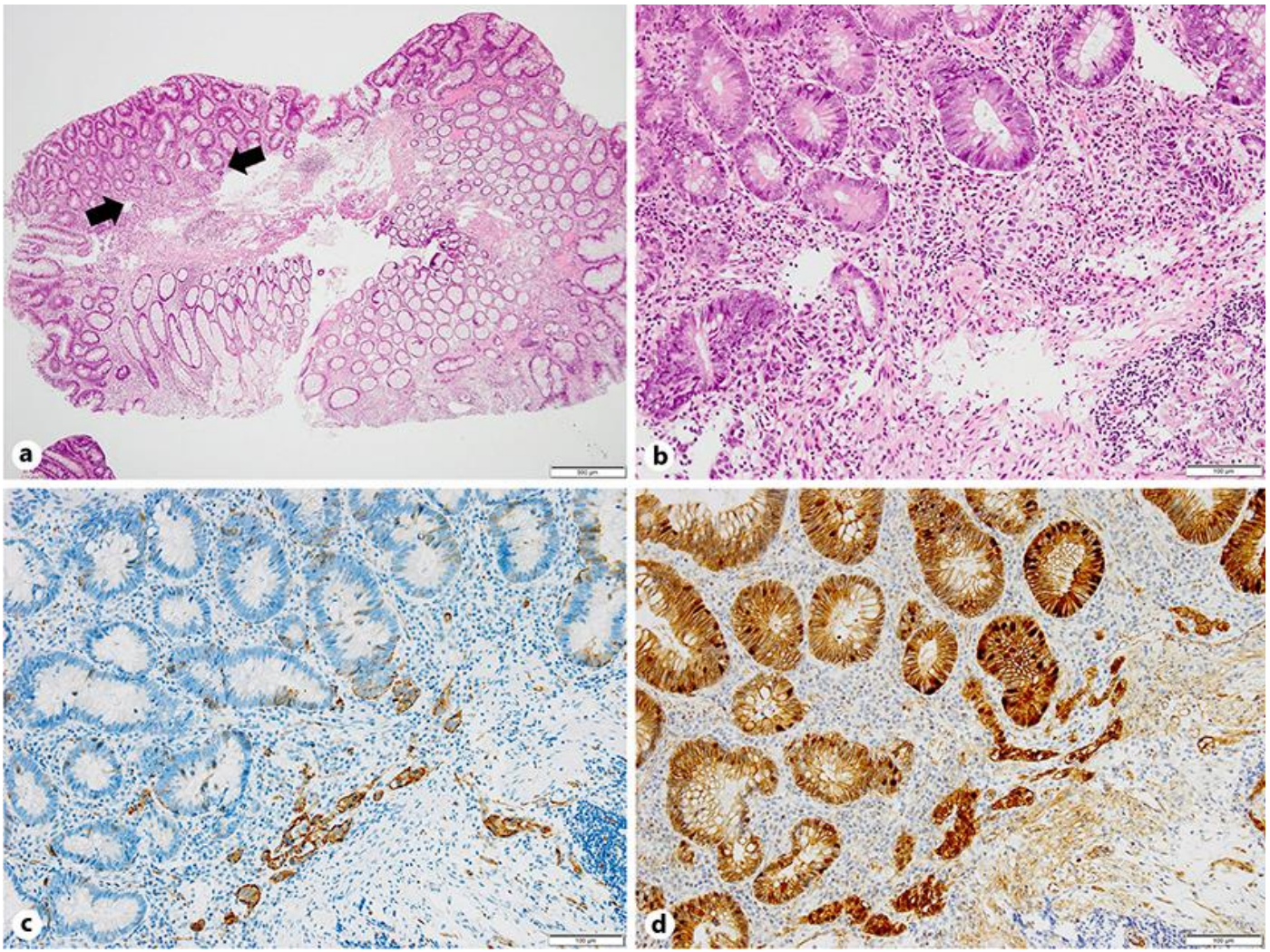

Fig. 2. a Low-power view of the polyp of case 1 reveals an adenomatous structure with a barely recognizable microcarcinoid component (black arrows). b Higher-power view reveals nests and cords of endocrine cells connected to adenomatous glands. c Immunohistochemical staining for synaptophysin reveals diffuse cytoplasmic reactivity of the microcarcinoid component only. $\mathbf{d}$ The nuclei were strongly immunoreactive for $\beta$-catenin. 

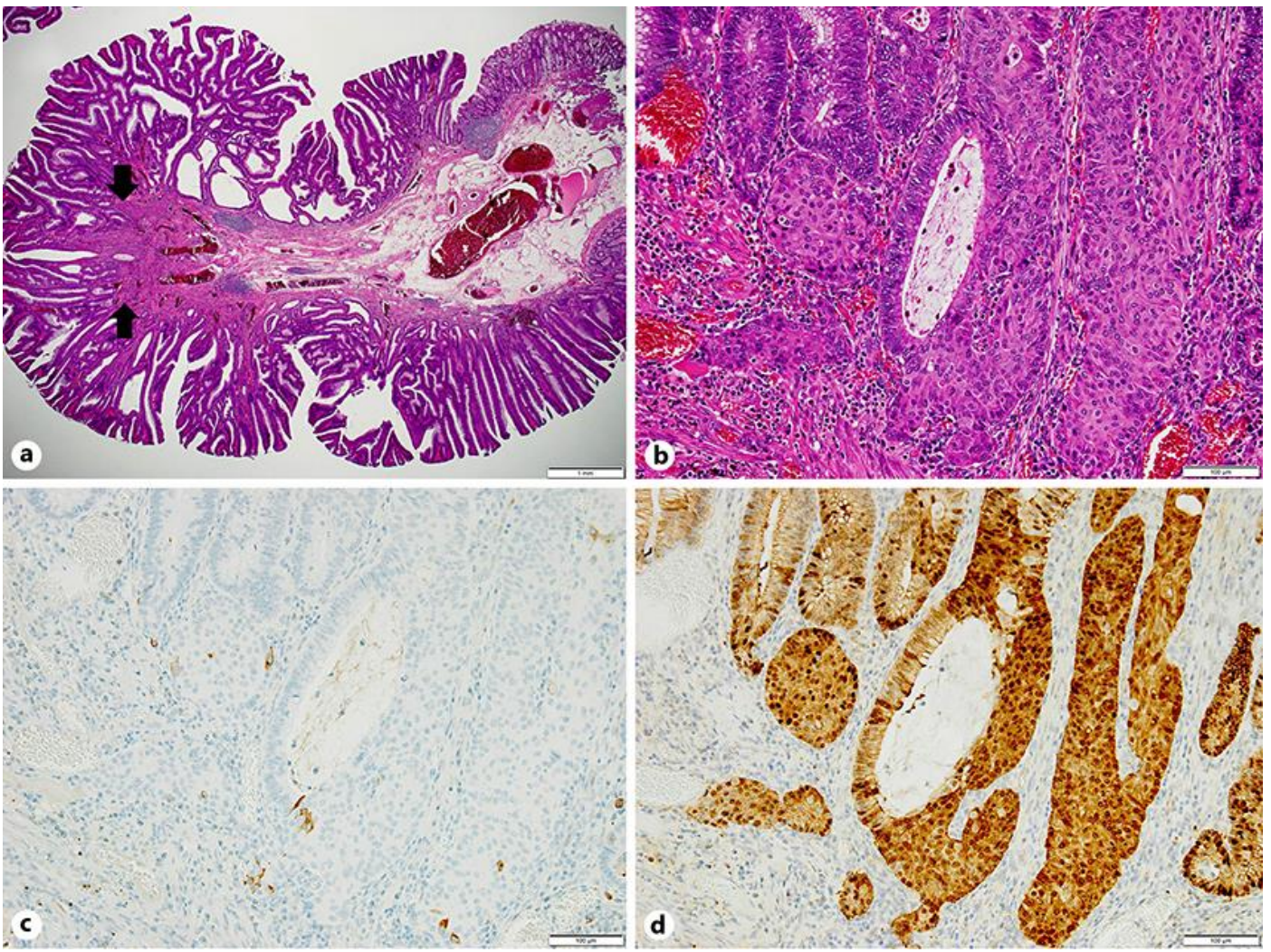

Fig. 3. a Low-power view of the polyp of case 2 reveals an adenomatous structure with a barely recognizable microcarcinoid component (black arrows). b Although, at a glance, the structure seems to be a squamous morula, the cytoplasmic granularity characteristic of neuroendocrine differentiation is evident. c The microcarcinoid components are weakly positive for synaptophysin. $\mathbf{d}$ The nuclei of the microcarcinoid components are much more strongly immunoreactive for $\beta$-catenin than those of the adenomatous components. 